\title{
STOPOVER ECOLOGY AND HABITAT SELECTION OF JUVENILE SWAINSON'S THRUSHES DURING FALL MIGRATION ALONG THE NORTHERN CALIFORNIA COAST
}

by

James Richard Tietz

\author{
A Thesis \\ Presented to \\ The Faculty of Humboldt State University \\ In Partial Fulfillment \\ Of the Requirements for the Degree \\ Masters of Science \\ In Natural Resources: Wildlife
}

April, 2006 
STOPOVER ECOLOGY AND HABITAT SELECTION OF JUVENILE SWAINSON'S THRUSHES DURING FALL MIGRATION ALONG THE NORTHERN CALIFORNIA COAST

by

James Richard Tietz

Approved by the Master's Thesis Committee:

Dr. Matthew D. Johnson, Major Professor

Date

Dr. Luke George, Committee Member

Date

Dr. Jeffrey M. Black, Committee Member

Date

Dr. Gary Hendrickson, Graduate Coordinator

Date

Donna E. Schafer, Dean for Research and Graduate Studies

Date 


\begin{abstract}
Stopover ecology and habitat selection of juvenile Swainson's Thrushes during fall migration along the northern California coast

James R. Tietz
\end{abstract}

I investigated stopover habitat selection of juvenile Swainson's Thrushes (Catharus ustulatus) during fall migration at the Lanphere Dunes along the Northern California Coast. For 26 birds captured and radio-tracked in 2002 and 2003, the average minimum length of stay was $8.9 \pm 1.0$ days. For 20 of the birds with a sufficient number of locations, the average home range size was $1.9 \pm 0.3$ ha. Thrushes showed no overall pattern of selection for forest type within the study area or for forest type used inside their home range. Fat and lean birds selected forest types similarly within the study area and their home ranges. However, locations occupied by lean birds had twice as much huckleberry shrub cover and 1.3 times more concealment than locations occupied by fat birds. Overall, there were 2.5 times more huckleberries at occupied than random locations, and lean birds had 2.9 times more berries than fat birds at occupied locations. Fecal analyses confirmed that huckleberries were a commonly consumed food. However, thrushes also ate arthropods and wax myrtle bracteoles. The overall lack of forest type selection coupled with differences in selection for cover and fruit abundance between fat and lean birds suggests that fat level may influence microsite selection. 


\section{ACKNOWLEDGEMENTS}

I am very thankful to the volunteers that helped with the banding at the Humboldt Bay Bird Observatory including Jessie Hunt, Joe Liebezeit, Jen Millard, Nicole Munkowitz, Mike Palladini, Becky Pierce, Christine Steele, and Chris Tonra. I also thank radio-telemetry technicians Naomi Avissar, Anna Clarke, Vanessa Harriman, Hanna Mounce, Laura Quattrini, Kerry Ross, Ellen Sherrill, and Christine Steele who spent numerous hours with me tracking "beeps" in the woods. I am especially grateful to Kim Barrier, Kim Gagnon, and Laura Quattrini for pushing their way through the dense thicket of shrubs to help me count huckleberries and to collect vegetation data. C.J. Ralph and Kim Hollinger graciously provided me with advice, logistical support, and data from the Humboldt Bay Bird Observatory. Carol Ralph helped with several plant identifications. I am also thankful to Andrea Pickart and the Lanphere Dunes Unit of the Humboldt Bay National Wildlife Refuge for logistical support and for permitting me to work on the refuge. Bill Bigg and Luke George provided statistical help. Matthew Perry, Chris Oneal, and Steven Steinberg from the HSU Spatial Analysis Lab helped with interpretation of aerial photos to create vegetation maps for GIS analyses. Committee members Luke George and Jeff Black provided constructive comments that greatly benefited this thesis. I am most grateful though to my advisor, Matt Johnson, for helping me with the project design, data analysis, and for spending long hours in the field with me. Funding for this project was provided by Research, Scholarship, and Creative Activity grants from Humboldt State University. 


\section{TABLE OF CONTENTS}

Page

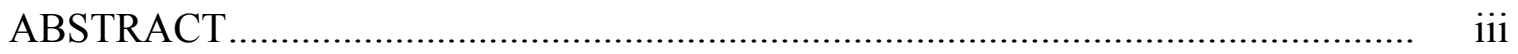

ACKNOWLEDGEMENTS ............................................................................. iv

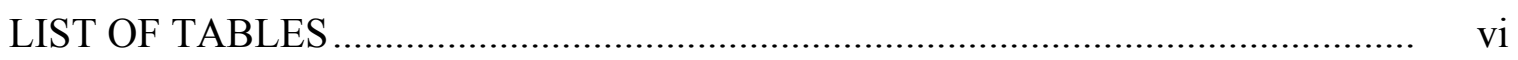

LIST OF FIGURES ………………….................................................... vii

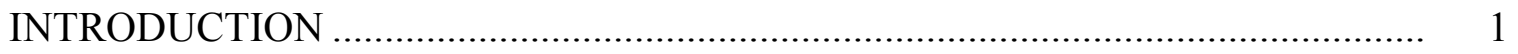

MATERIAL AND METHODS ............................................................................... 4

Capture and Marking ................................................................................ 4

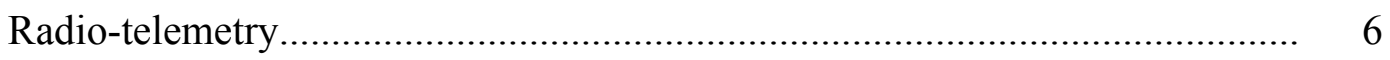

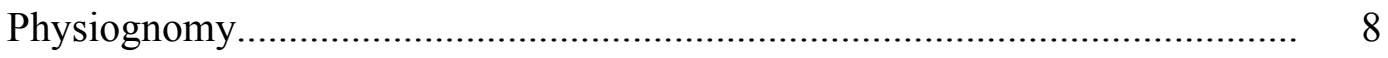

Fruit Resources ........................................................................................

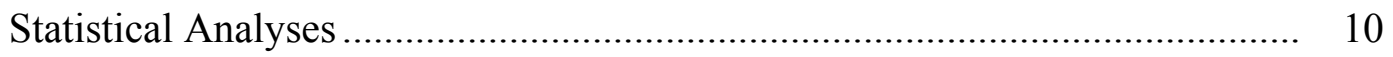

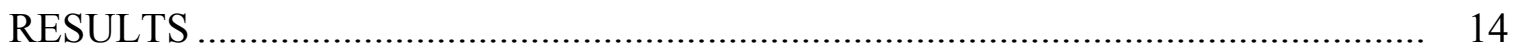

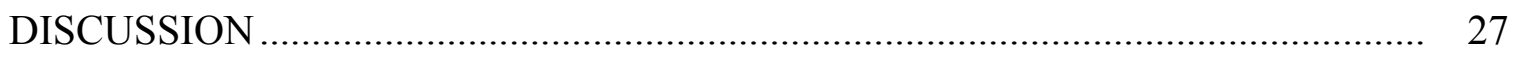

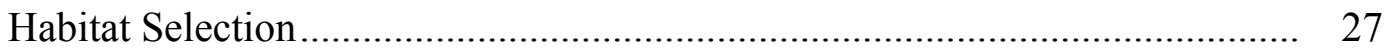

Stopover Strategies: Fat vs. Lean................................................................ 31

Conservation Implications …………...................................................... 33

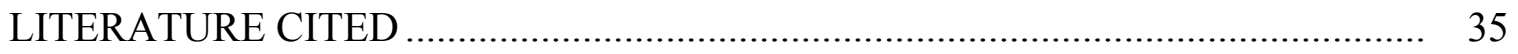




\section{LIST OF TABLES}

Table

1 Mean shrub cover measurements (vegetation over two $10 \mathrm{~m}$ line intercepts $\pm 1 \mathrm{SE}$ ) of the five most common shrub species within Swainson's Thrush home ranges at random broadleaf $(n=12)$ and conifer forest points $(n=98)$, occupied and random points $(n=22)$, points occupied by fat $(n=9)$ and lean $(n=12)$ birds, and data from occupied points collected in $2002(n=$ $7)$ and $2003(n=15)$. The "combined" category is the sum of the five shrub species.................................................................. 


\section{LIST OF FIGURES}

Figure

1 Map of study area showing vegetation types and location of mist nets and trails. ...

2 Distance ratios of individual Swainson's Thrushes $(n=20)$ to each vegetation type at Johnson's $2^{\text {nd }}$ order habitat selection showing a lack of overall selection for vegetation type. The dashed line at 1.0 shows where an individual's observed distance would equal the expected distance to that vegetation type. Individuals with values less than 1.0 show selection for that vegetation type, while individuals with values greater than 1.0 show avoidance. Closed and open symbols represent birds tracked in 2002 and 2003 respectively. Circles, triangles, and squares represent lean, fat, and intermediate birds respectively.........................................

3 Distance ratios of individual Swainson's Thrushes $(n=20)$ to each vegetation type at Johnson's $3^{\text {rd }}$ order habitat selection showing a lack of overall selection for vegetation type. The dashed line at 1.0 shows where an individual's observed distances would equal the expected distance to that vegetation type. Individuals with values less than one show selection for that vegetation type, while individuals with values greater than one show avoidance. Closed and open symbols represent birds tracked in 2002 and 2003 respectively. Circles, triangles, and squares represent lean, fat, and intermediate birds respectively..........................................

4 Mean huckleberry cover values $( \pm 1 \mathrm{SE})$ of fat and lean Swainson's Thrushes from occupied and random points $(n=22)$. Huckleberry cover $(\mathrm{m})$ was measured along two $10 \mathrm{~m}$ line intercepts at five occupied and five random locations within each bird's home range.................................

5 Mean concealment values ( $\pm 1 \mathrm{SE})$ for fat and lean Swainson's Thrushes at occupied and random points $(n=22)$. Concealment values are the proportion of 100 squares of a $1 \mathrm{~m}^{2}$ checkerboard greater than $50 \%$ obscured through $3 \mathrm{~m}$ of vegetation at five occupied and five random locations within

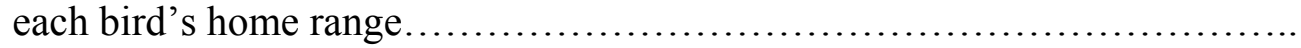

6 Spearman-rank correlation between concealment and huckleberry cover. Concealment and huckleberry cover values are ranks from five random locations within each bird's home range. 


\section{LIST OF FIGURES (CONTINUED)}

7 Mean numbers of unripe, ripe, and overripe huckleberries ( $\pm 1 \mathrm{SE})$ at occupied and random plots $\left(4 \mathrm{~m}^{2}\right)$ within Swainson's Thrush home ranges $(n=22)$

8 Mean values $( \pm 1 \mathrm{SE})$ of huckleberries counted within $4 \mathrm{~m}^{2}$ occupied plots for fat $(n=7)$ and lean Swainson's Thrushes $(n=15)$... 


\section{INTRODUCTION}

For migratory birds, migration is the most dangerous and unpredictable period of their annual cycle (Sillet and Holmes 2002) and thus has a profound impact upon an individual's fitness. Individuals that cope poorly with the hazards and stresses of migration may succumb to starvation or predation, arrive too weak or too late at their destination to obtain and defend a breeding or non-breeding territory, or suffer reduced reproductive success (Moore 2000). Since stopover represents a much greater proportion of the migratory phase than flying (Hedenström and Alerstam 1997), the selection of appropriate stopover sites and habitats for resting, refueling, and keeping safe from predators is critical to the success of a migrant bird (Schaub and Jenni 2001).

The energetic condition of an arriving migrant to a stopover site may affect which stopover strategy is favored. Fat and lean birds have been shown in previous research to select different stopover habitats (Moore and Aborn 2000), forage using different behaviors (Loria and Moore 1990), and remain at stopover sites for different lengths of time (Yong and Moore 1997). One line of reasoning suggests that in order for lean birds to continue their migration, they should select stopover habitats rich in food types that will meet their physiological demands and allow them to quickly regain body mass and fat stores. Fat birds, on the other hand, simply need to conserve energy and avoid predators by taking refuge in dense habitats since they may already have sufficient energy stores to continue migration (Moore and Aborn 2000). This may be most relevant for time-constrained individuals such as birds heading north to their breeding grounds 
where early nest initiation dates are correlated with increased reproductive success (Norris et al. 2004, Smith and Moore 2005) or for adults heading south that need to reclaim a winter territory (Stutchbury 1994, Schmaljohann and Dierschke 2005). For juvenile migrants heading south for their first time, there may not be a clear advantage to arriving on the winter grounds as quickly as possible because dominant adults may evict a subordinate juvenile (Marra 2000). If food is relatively abundant along the migration route, as it may be for frugivores in the fall (Thompson and Willson 1979, Burns 2002), then a juvenile migrant might benefit during stopover by conserving energy, avoiding predators, and using risk-averse behaviors while foraging (Alerstam and Lindström 1990, Hedenström and Alerstam 1997).

I used telemetry to investigate stopover habitat selection for juvenile Swainson's Thrushes (Catharus ustulatus) during fall migration along the Northern California Coast. Because habitat selection can occur at a variety of scales (Johnson 1980), I tested whether the observed selection of forest types by thrushes differed from expected within the 66 ha study area $\left(2^{\text {nd }}\right.$ order selection $)$ and within individual bird's home ranges $\left(3^{\text {rd }}\right.$ order selection). Since differences in food availability and predation risk among habitats have been shown to affect stopover site selection (Hutto 1985, Lindström 1990, Sapir et al. 2004), I examined whether fruit availability, shrub cover, and concealment differed between occupied and random locations. I also compared the habitat selection of fat and lean birds to determine whether energetic condition upon arrival plays a role in shaping stopover strategy. In addition, I analyzed fecal samples to determine what foods were 
being consumed, how prevalent these food types were in the birds' diet, and whether the fecal samples of fat and lean birds differed. 


\section{MATERIALS AND METHODS}

I conducted my study at the Lanphere Dunes unit of the Humboldt Bay National Wildlife Refuge and two adjacent private properties on the North Spit of the Humboldt Bay dunes (Figure 1). This location is well situated for concentrating migrant songbirds because it contains a narrow strip of forest bordered on the west by sand dunes and the Pacific Ocean and on the east by Humboldt Bay, tidal estuary, and dairy pasture.

\section{Capture and Marking}

In 2002 and 2003, I captured Swainson's Thrushes in 13 12-meter mist nets placed in coniferous forest and 11.5 placed in broadleaf forest (Figure 1). Because adult fall migrants are rare along the immediate coast (Ralph 1971), I could not examine age effects, and thus focused my study on juveniles. Since two-thirds of these nets were operated in a year-round constant effort by the Humboldt Bay Bird Observatory, I followed their operating and banding procedures. Mist nets were opened at dawn on Wednesdays, Fridays, and Sundays for five hours from 4 September to 10 October. I chose this period after examining ten years of previous banding data (Humboldt Bay Bird Observatory unpublished data), which indicated that most local juveniles have left the immediate area by the end of August and that the peak of fall migration of juvenile Swainson's Thrushes occurs during these dates.

Mist nets were checked every half hour and captured birds were brought to the banding station in brown paper bags for processing. All birds were aged by degree of 


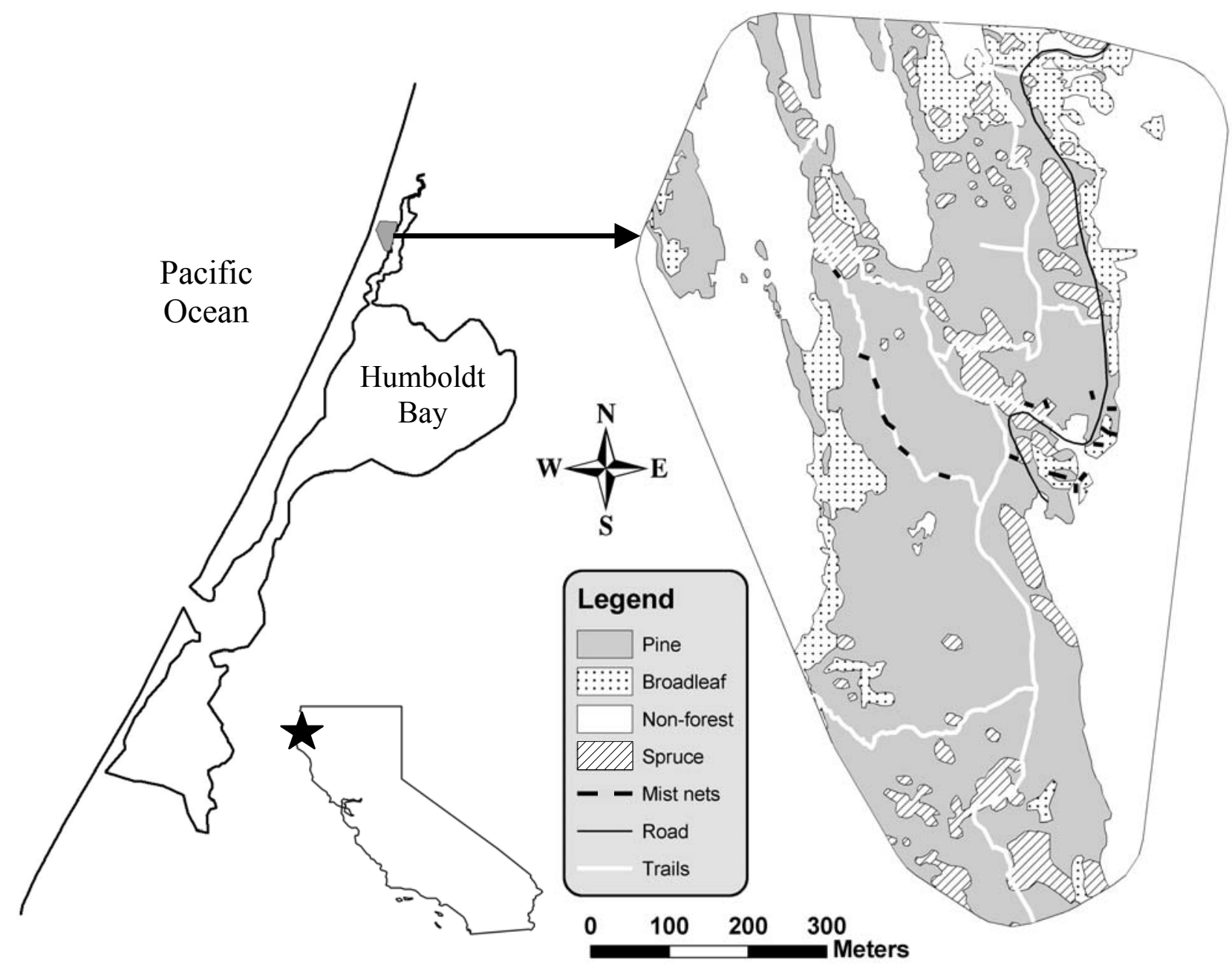

Figure 1. Map of study area showing vegetation types and location of mist nets and trails. 
skull ossification. Standard morphometric measurements were taken (Ralph et al. 1993), and each bird received a uniquely numbered U.S. Geological Survey band. Energetic condition was determined by the amount of subcutaneous fat in the furcular hollow. Birds with their furcular hollow less than $5 \%$ full were considered lean, while birds with their furcular hollow greater than half full were considered fat. Birds with intermediate fat scores were excluded from analyses where energetic condition was used as an independent variable. Newly captured juvenile birds not exhibiting physical abnormalities and that had completed their first pre-basic molt were fitted with radio transmitters (Holohil Systems Ltd.) that had a minimum battery life of three weeks. Transmitters were attached using a leg harness system designed for songbirds (Rappole and Tipton 1991). In 2002, I used a non-elastic thread for the harness, but in 2003 I used elastic thread, which greatly expedited the harnessing procedure. Birds were released within $10 \mathrm{~m}$ of the net in which they were captured during the next routine net check. All capture and handling methods were approved by Humboldt State University's Institutional Animal Care and Use Committee (02/03.W.05A).

\section{Radio-telemetry}

Radio-telemetry occurred six days per week and consisted of morning (07:00 to 11:00) and afternoon (13:00 to 17:00) sessions on days when the mist nets were not in operation. On banding days radio telemetry was done only in the afternoon. During a session, two or three observers radio-tracked the movement of each bird to obtain biangulated or triangulated positions respectively from marked reference points located 
with a Trimble GeoExplorer 3 and post-processed to minimize error. During a bird's first three tracking sessions (e.g. afternoon, morning, afternoon), locations were obtained every five minutes for one hour; observers used 2-way radios to synchronize their work. Thereafter, bird locations were obtained once per day. Minimum stopover duration for all radio-tagged birds was estimated as the number of days between capture and the day the bird left the study area. A bird was considered to have left the study area, if within three weeks of a bird receiving a transmitter (battery life of the transmitter) its radio signal could no longer be detected after a thorough search of Lanphere Dunes and the surrounding properties. Daily checks were conducted for the remainder of the battery life to ensure that the bird did not return to the study area. All birds either left the study area prior to their battery running out of power, or the bird died.

Radio-telemetry location errors were determined using the computer program LOAS 3.0.2 (LOAS 2004). Locations with error areas (ellipses for triangulated points and polygons for biangulated points) larger than $400 \mathrm{~m}^{2}$ were not used, as areas larger than this could cause bias and lead to a type II error (Conner and Plowman 2001). A pilot study conducted in 2001 suggested that a minimum of 20 locations were necessary to define $90 \%$ of a bird's home range, so birds with fewer than 20 acceptable locations were not used in this analysis. Acceptable locations were imported into ArcView version 3.3 (ESRI 2002b) where the Animal Movement extension (Hooge and Eichenlaub 2000) was used to create minimum convex polygon home ranges. These home ranges were then overlaid onto a vegetation map created from aerial photographs that delineated four vegetation types: pine, spruce, broadleaf, and non-forest. Pine is composed mostly of 
beach pine (Pinus contorta contorta), spruce of Sitka spruce (Picea sitchensis), and broadleaf of red alder and willow (Alnus rubra and Salix spp.). Non-forest is composed of sand dune, dune mat, pasture, tidal estuary, and buildings. Since the shrub composition and density in pine and spruce vegetation types were found to be similar, they were combined for several analyses into a forest type called conifer. Only the forested vegetation types were included in habitat analyses since Swainson's Thrushes rarely use non-forested areas during stopover (Mack and Yong 2000) and radio-tagged birds were never seen or detected in non-forest vegetation types. Furthermore, since mist-nets were concentrated across the center of the study area, I constrained my analyses to a 66 ha area by placing a $77 \mathrm{~m}$ buffer around a minimum convex polygon constructed from locations of all birds. This buffer distance was derived by taking the radius of a circle that was the size of the mean area of the stopover home ranges. The resulting study area was $72.4 \%$ pine, $13.5 \%$ spruce, and $14.0 \%$ broadleaf forest.

\section{Vegetation Measurements}

During winter, spring, and fall of 2004, I measured understory structure and vegetation composition to determine their role in habitat selection. Using a GPS unit (Garmin XL 12-channel), another field technician and I located five occupied and five random points within each bird's home range. Occupied points were estimated from telemetry while random points were determined with the Animal Movement Extension (Hooge and Eichenlaub 2000) in ArcView version 3.3 (ESRI 2002b). At each point, I measured vegetative cover using a line intercept technique, which consisted of laying out 
a $10 \mathrm{~m}$ tape centered on the point in both the north-south and east-west directions and measuring the distance that each plant species covered the tape in decimeters. Only plants $<3 \mathrm{~m}$ and $>\sim 0.5 \mathrm{~m}$ tall were measured (i.e. shrubs).

Understory structure was measured by taking two concealment readings at the same occupied and random points as for the vegetative cover. A $1 \mathrm{~m}^{2}$ cloth checkerboard with $10010 \times 10 \mathrm{~cm}$ squares was held $0.5 \mathrm{~m}$ above the ground at each point, and I stood $3 \mathrm{~m}$ to the east and south and counted the number of squares visible. This value was then subtracted from one hundred to obtain percentage concealment. To maintain consistency, I was the only observer.

To maximize my time available to track birds in the fall, I measured coniferous habitats in the winter and spring because the understory was almost completely evergreen and therefore did not change seasonally. However, I measured the broadleaf habitat in the fall because it had a higher proportion of deciduous vegetation and would more closely approximate what the thrushes experienced. By regressing concealment from all locations against Julian date, I verified that concealment measurements did not vary by season $\left(F_{1,218}=0.20, P=0.66\right)$.

\section{Fruit Resources}

Fruit availability was measured by counting berry abundance at occupied and random locations one to two weeks after a bird's arrival. In 2002, huckleberries (Vaccinium ovatum), blackberries (Rubus ursinus), salal berries (Gaultheria shallon), and bearberries (Arctostaphylos uva-ursi) were counted in a $4 \mathrm{~m}^{2}$ plot at five occupied and 
five random points within each bird's home range located using the same technique as for vegetation measurements (see above). When berries were too abundant to be counted individually, they were estimated within a $1 \mathrm{~m}^{3}$ spherical counting frame and extrapolated to a $4 \mathrm{~m}^{2}$ plot (sensu Stransky and Halls 1980). In 2003, only huckleberries were counted since they were by far the most abundant berry in 2002 and the only one that showed promise as a factor in the birds' habitat selection. Huckleberries were classified as ripe (purple to black), unripe (green to reddish), or overripe (shriveled) and tallied separately.

In 2002 and 2003, fecal samples were collected from paper bags used to transport thrushes and samples were preserved in alcohol until processing. Berries from all fruiting plants at Lanphere Dunes were collected and preserved for comparative purposes. Fecal samples were examined using a dissecting microscope and all seeds were counted and identified. Wax myrtle (Myrica californica) bracteoles and arthropod body parts were noted to be either present or absent.

\section{Statistical Analyses}

I used Euclidean distance analysis to determine whether Swainson's Thrushes were selecting vegetation types during their stopover (Conner and Plowman 2001, Conner et. al. 2003) at Johnson's (1980) $2^{\text {nd }}$ (selection within study area) and $3^{\text {rd }}$ (selection within home range) orders. In this analysis, selection is revealed if the distance from occupied points to a particular vegetation type is significantly shorter than from random points. Using the Animal Movement Extension (Hooge and Eichenlaub 2000) in 
ArcView version 3.3 (ESRI 2002b), I generated 3500 random points within the study area and 500 points within each bird's home range. The average distance from occupied and random points to each vegetation type within the study area was calculated to obtain observed and expected distances respectively to each vegetation type using the Near command in ArcInfo version 8.2 (ESRI 2002a).

Second-order selection was determined by creating a ratio of the expected distance from random points within each home range to each vegetation type divided by the overall expected distance (from the 3500 random points) to each vegetation type (Perkins and Conner 2004). Third-order selection was determined by creating a ratio of the average distance from occupied points to each vegetation type divided by the expected distance from random points within each home range to each vegetation type (Perkins and Conner 2004). Ratios less than one indicated selection (i.e. the bird was closer to a vegetation type than expected), while ratios greater than one indicated avoidance (Conner and Plowman 2001). To determine if birds were selecting forest "edge" habitats at either order, I examined whether birds were closer to non-forest than expected. I used a Wilk's lambda multivariate analysis of variance (MANOVA) in SAS version 8.2 (SAS Institute 2001) to test for overall selection in both habitat orders (Conner and Plowman 2001). If overall selection was found in either order, I determined which vegetation types had distance ratios statistically different than 1.0 by using onesample $t$-tests. This was followed by ranking the vegetation types through pairwise comparisons. In addition to this general test of habitat selection, I included the energetic 
condition (fat or lean) of the bird and year as variables in two separate analyses to determine their effects on habitat selection.

For shrub cover, concealment, and counts of berries, the following four factors were considered: point type (occupied or random), energetic condition of the bird (fat or lean), year (2002 or 2003), and vegetation type (conifer or broadleaf). For the first three factors, I eliminated pseudoreplication and reduced zeros in the dataset by averaging data for the five occupied and five random points per bird (i.e., sample size equals the number of birds in the test). However, since individual home ranges often spanned both conifer and broadleaf habitats, this factor was not averaged and the individual data points were analyzed. Multi-way analysis of variance (ANOVA) of the first three factors simultaneously was not appropriate given the small sample size $(n=21)$. Therefore, I used pairwise comparisons to determine statistical differences within factors.

Since no single transformation of the data could normalize all the data and no transformation of the data comparing vegetation types was adequate due to a large number of zeros in the datasets, I used Hotelling's $T^{2}$ in NCSS (Hintze 2001) to take advantage of the randomization tests. 50,000 Monte Carlo samples were used for all tests to obtain stable $P$-values. Hotelling's $T^{2}$ can be used as a multivariate or univariate Student's $t$-test. Therefore I used Hotelling's paired $T^{2}$ to compare occupied and random points, and Hotelling's two-sample $T^{2}$ to compare data from 2002 and 2003, fat and lean birds at occupied points, and broadleaf and conifer forests at random points. Based on the 50,000 random samples, the definition of a $P$-value in these tests is the proportion of overlap between the distributions of the means of the two sample populations. Thus, 
there are no test statistics or degrees of freedom for these tests, and I report a $P$-value and sample size for each analysis. NCSS (Hintze 2001) was used for all analyses except

Euclidean distance-based analyses (SAS, see above). An alpha value of 0.05 was used for all tests, and descriptive statistics in text are reported as means $\pm 1 \mathrm{SE}$. 


\section{RESULTS}

During the fall migration of 2002 and 2003, 28 Swainson's Thrushes were captured, tracked, and analyzed. However, seven of these birds did not remain long enough in the study area to obtain 20 or more useable locations and could not be used for Euclidean distance-based analyses. Another bird could not be included in any analyses because it either lost its transmitter or died (unrecoverable transmitter was motionless for 19 days until battery died). Of the 20 birds that had greater than 20 useable locations, 10 of these birds were initially caught in nets placed in broadleaf habitat, while the other 10 were captured in nets in coniferous habitat. Upon initial capture, nine of these birds were considered fat, 10 were lean, and one received an intermediate fat score. One of the fat birds was killed by a Cooper's Hawk (Accipiter cooperi) after we had obtained 20 locations and was not used in stopover duration calculations.

For 26 birds, the average minimum stopover duration was $8.9 \pm 1.0$ days. There was no significant difference in stopover duration between fat $(10.5 \pm 1.6$ days, $n=8)$ and lean birds $(8.6 \pm 1.3$ days, $n=17, P=0.4)$. Birds stayed 1.8 times longer in 2003 (11.3 \pm 1.2 days, $n=14)$ than $2002(6.2 \pm 1.2$ days, $n=12, P<0.01)$. For birds with greater than 20 locations $(n=20)$, the average home range size was $1.9 \pm 0.3$ ha. The home range size of lean birds $(2.5 \pm 0.5$ ha, $n=10)$ was twice that of fat birds $(1.2 \pm 0.3$ ha, $n=9, P=0.05)$, but there was no significant difference between years $2002(2.0 \pm 0.4$ ha, $n=7)$ and $2003(1.8 \pm 0.4$ ha, $n=13, P=0.7)$. 
Juvenile thrushes showed no consistent selection of forest types within the study area $\left(2^{\text {nd }}\right.$ order; Figure $\left.2 ; F_{4,16}=1.21, P=0.34\right)$ or within their home ranges $\left(3^{\text {rd }}\right.$ order; Figure $3 ; F_{4,16}=1.73, P=0.19$ ). Furthermore, energetic condition (fat or lean) did not affect forest selection at the $2^{\text {nd }}$ order $\left(F_{4,15}=0.93, P=0.48\right)$, or the $3^{\text {rd }}$ order $\left(F_{4,15}=\right.$ $2.04, P=0.14)$. Forest type selection was not affected by year $(2002$ or 2003$)$ at the $2^{\text {nd }}$ order (Figure $\left.2 ; F_{4,16}=1.21, P=0.34\right)$ or the $3^{\text {rd }}$ order $\left(\right.$ Figure $\left.3 ; F_{4,16}=1.73, P=0.19\right)$. Reanalyzing data using conifer as a single forest type instead of spruce and pine separately showed no overall selection at the $2^{\text {nd }}$ (Figure $2 ; F_{3,17}=1.08, P=0.38$ ) and $3^{\text {rd }}$ orders $\left(F_{3,17}=2.18, P=0.13\right)$. However, pooling masks individual variation (Thomas and Taylor 1990), and the bimodal distance-ratio distribution visible for the pine vegetation type at the $2^{\text {nd }}$ order (Figure 2 ) became even more extreme when pine and spruce forest types were combined into conifer forest. Thus, while the "average" thrush showed no selection or avoidance of conifer, some individual thrushes appear to strongly select conifer while others strongly avoid it within their home ranges.

Using the line intercept method, I measured 33 species of plants that occurred in the shrub layer, of which only five (blackberry, huckleberry, salal, silk tassel [Garrya elliptica], and wax myrtle) averaged greater than one meter of cover per point (i.e., $>5 \%$ of the $20 \mathrm{~m}$ measured). Thus, I restricted most of my analyses to these five shrub species because they all produce berries in the fall and were thus potential food sources for Swainson's Thrushes. Blackberry, huckleberry, salal, and silk tassel each differed significantly in shrub cover between conifer and broadleaf vegetation types, and wax myrtle was nearly significant (Table 1). Since some shrub species were common in one 


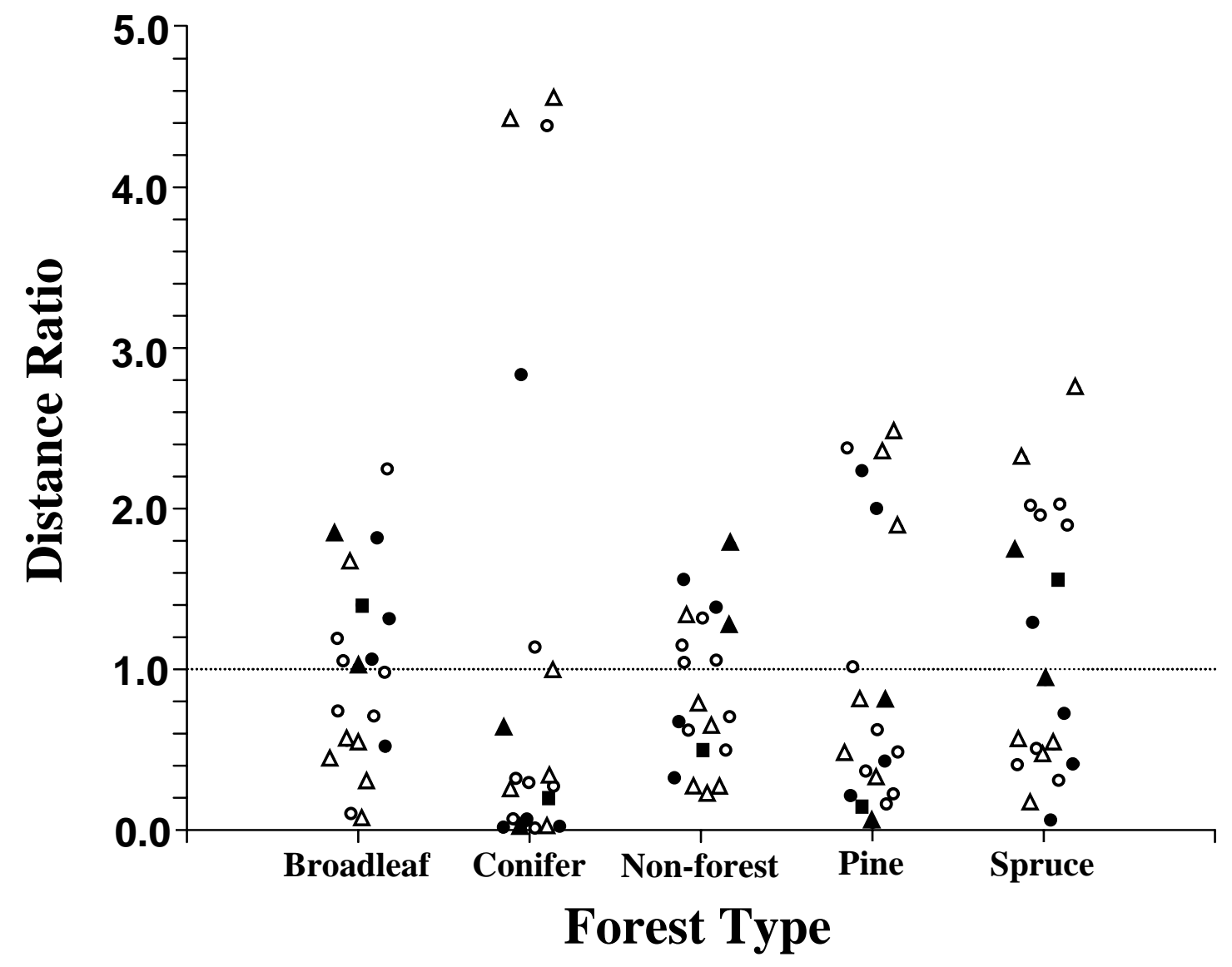

Figure 2. Distance ratios of individual Swainson's Thrushes $(n=20)$ to each vegetation type at Johnson's $2^{\text {nd }}$ order habitat selection showing a lack of overall selection for vegetation type. The dashed line at 1.0 shows where an individual's observed distance would equal the expected distance to that vegetation type. Individuals with values less than 1.0 show selection for that vegetation type, while individuals with values greater than 1.0 show avoidance. Closed and open symbols represent birds tracked in 2002 and 2003 respectively. Circles, triangles, and squares represent lean, fat, and intermediate birds respectively. 


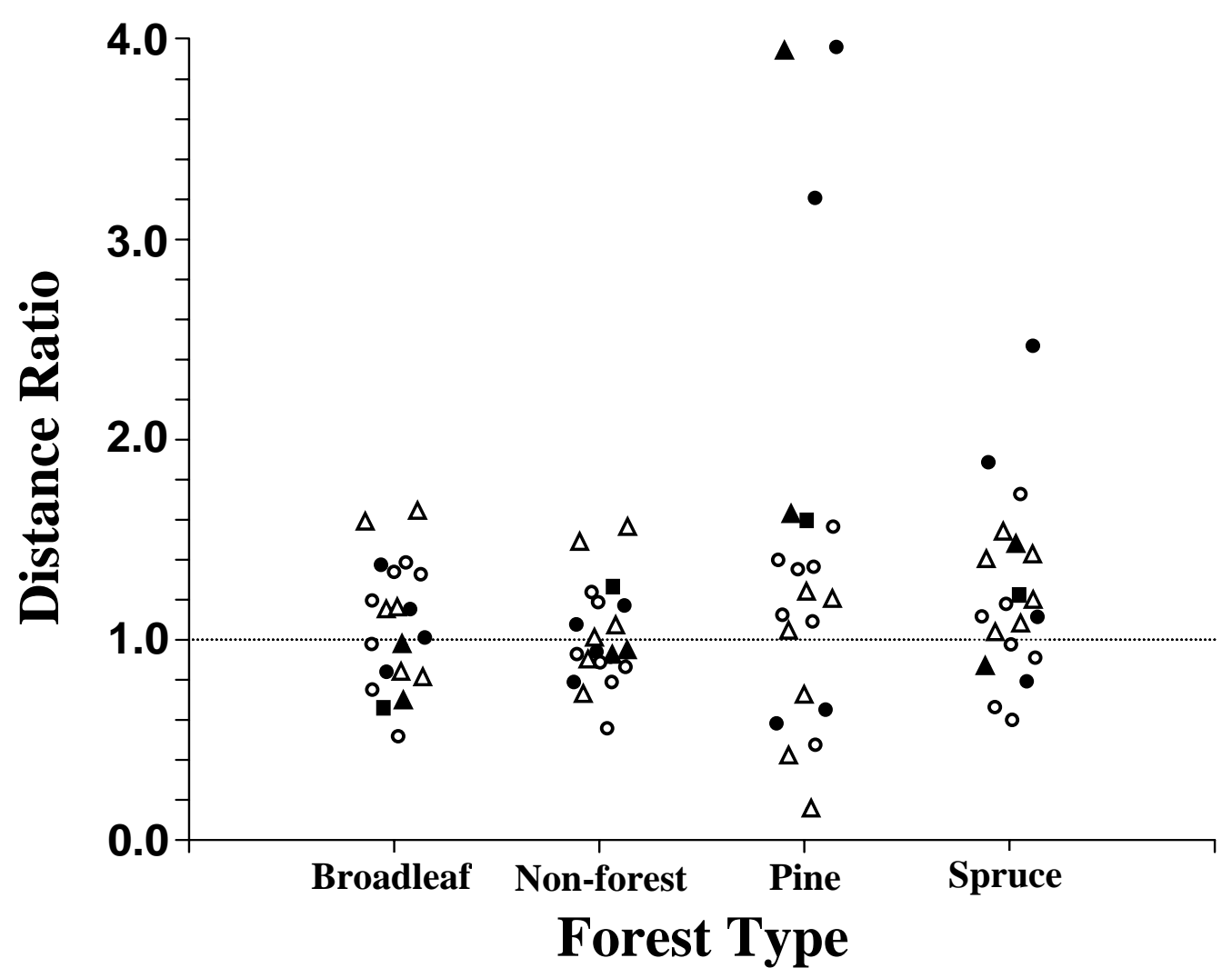

Figure 3. Distance ratios of individual Swainson's Thrushes $(n=20)$ to each vegetation type at Johnson's $3^{\text {rd }}$ order habitat selection showing a lack of overall selection for vegetation type. The dashed line at 1.0 shows where an individual's observed distances would equal the expected distance to that vegetation type. Individuals with values less than 1.0 show selection for that vegetation type, while individuals with values greater than 1.0 show avoidance. Closed and open symbols represent birds tracked in 2002 and 2003 respectively. Circles, triangles, and squares represent lean, fat, and intermediate birds respectively. 
Table 1. Mean shrub cover measurements (vegetation over two $10 \mathrm{~m}$ line intercepts $\pm 1 \mathrm{SE}$ ) of the five most common shrub species within Swainson's Thrush home ranges at random broadleaf $(n=12)$ and conifer forest points $(n=98)$, occupied and random points $(n=22)$, points occupied by fat $(n=9)$ and lean $(n=12)$ birds, and data from occupied points collected in $2002(n=7)$ and $2003(n=15)$. The "combined" category is the sum of the five shrub species.

\begin{tabular}{|c|c|c|c|c|c|c|c|c|c|c|c|c|}
\hline \multirow[b]{2}{*}{ Shrub species } & \multicolumn{3}{|c|}{ Vegetation type } & \multicolumn{3}{|c|}{ Point type } & \multicolumn{3}{|c|}{ Energetic level } & \multicolumn{3}{|c|}{ Year } \\
\hline & Broadleaf & Conifer & $P$ & Occupied & Random & $P$ & Fat & Lean & $P$ & 2002 & 2003 & $P$ \\
\hline Blackberry & $10.2 \pm 1.8$ & $1.1 \pm 0.3$ & $<0.001$ & $3.0 \pm 0.7$ & $2.1 \pm 0.6$ & 0.09 & $4.1 \pm 1.1$ & $2.5 \pm 0.9$ & 0.27 & $1.1 \pm 0.7$ & $3.9 \pm 0.9$ & 0.05 \\
\hline Huckleberry & $1.4 \pm 1.0$ & $9.8 \pm 0.7$ & $<0.001$ & $8.6 \pm 0.9$ & $8.9 \pm 0.6$ & 0.67 & $5.6 \pm 1.0$ & $10.5 \pm 1.1$ & $<0.01$ & $10.4 \pm 1.8$ & $7.8 \pm 1.0$ & 0.20 \\
\hline Salal & 0.0 & $2.8 \pm 0.4$ & 0.01 & $2.5 \pm 0.6$ & $2.5 \pm 0.5$ & 0.99 & $3.2 \pm 1.4$ & $2.1 \pm 0.5$ & 0.44 & $3.2 \pm 1.4$ & $2.1 \pm 0.7$ & 0.44 \\
\hline Silk tassel & 0.0 & $1.7 \pm 0.3$ & $<0.05$ & $1.3 \pm 0.3$ & $1.6 \pm 0.2$ & 0.49 & $1.3 \pm 0.5$ & $1.5 \pm 0.3$ & 0.74 & $1.1 \pm 0.4$ & $1.4 \pm 0.3$ & 0.57 \\
\hline Wax myrtle & $3.3 \pm 1.1$ & $1.6 \pm 0.3$ & 0.07 & $2.5 \pm 0.4$ & $1.8 \pm 0.3$ & 0.18 & $2.2 \pm 0.7$ & $2.3 \pm 0.5$ & 0.90 & $1.8 \pm 0.9$ & $2.8 \pm 0.5$ & 0.27 \\
\hline Combined & $14.9 \pm 2.1$ & $17.0 \pm 0.8$ & 0.41 & $18.0 \pm 0.6$ & $16.8 \pm 0.7$ & 0.11 & $16.4 \pm 1.0$ & $18.9 \pm 0.6$ & 0.02 & $23.5 \pm 0.4$ & $23.4 \pm 1.3$ & 0.97 \\
\hline
\end{tabular}


vegetation type but not the other, conifer and broadleaf did not differ when shrubs were combined (Table 1). For occupied and random points $(n=22)$, no overall difference was detected using the multivariate Hotelling's $T^{2}$ for the five most common shrub species $(P$ $=0.35$; Table 1). For all 33 species of shrubs measured there was significantly more overall shrub cover at locations occupied by lean than fat birds (lean birds $=25.0 \pm 1.3 \mathrm{~m}$, $n=12$, fat birds $=21.2 \pm 1.0 \mathrm{~m}, n=9, P=0.02$ ), which was primarily caused by huckleberry being twice as common at points occupied by lean than fat birds (Table 1). Huckleberry shrub cover was also significantly different at random points within fat and lean birds' home ranges; points in lean birds' home ranges had 1.4 times more huckleberry cover than points in fat birds' home ranges $(P=0.03$; Figure 4$)$.

For all birds pooled, concealment did not differ between broadleaf $(n=12)$ and conifer $(n=98)$ at random points within the birds' home ranges (broadleaf $=0.72 \pm 0.10$, conifer $=0.70 \pm 0.03, P=0.86$ ). A 2-way ANOVA (concealment data for these variables were normally distributed) revealed a strong effect of energetic condition (lean birds = $0.76 \pm 0.02$, fat birds $\left.=0.65 \pm 0.02, F_{1,38}=12.4, P<0.001\right)$, no difference between occupied and random points (occupied $=0.72 \pm 0.02$, random $=0.71 \pm 0.02, F_{1,38}=0.19$, $P=0.66)$, and a non significant interaction between these two factors $\left(F_{1,38}=3.7, P=\right.$ 0.06, Figure 5). Concealment and huckleberry cover at random locations are strongly and positively correlated $\left(r_{\mathrm{s}}=0.61, P<0.001\right.$; Figure 6$)$.

The combined berry datasets from 2002 and $2003(n=22$ home ranges) indicated that there were, on average, 118.6 more huckleberries at points occupied by Swainson's Thrushes than randomly chosen points within their home range $(P=0.04$; Figure 7$)$. 


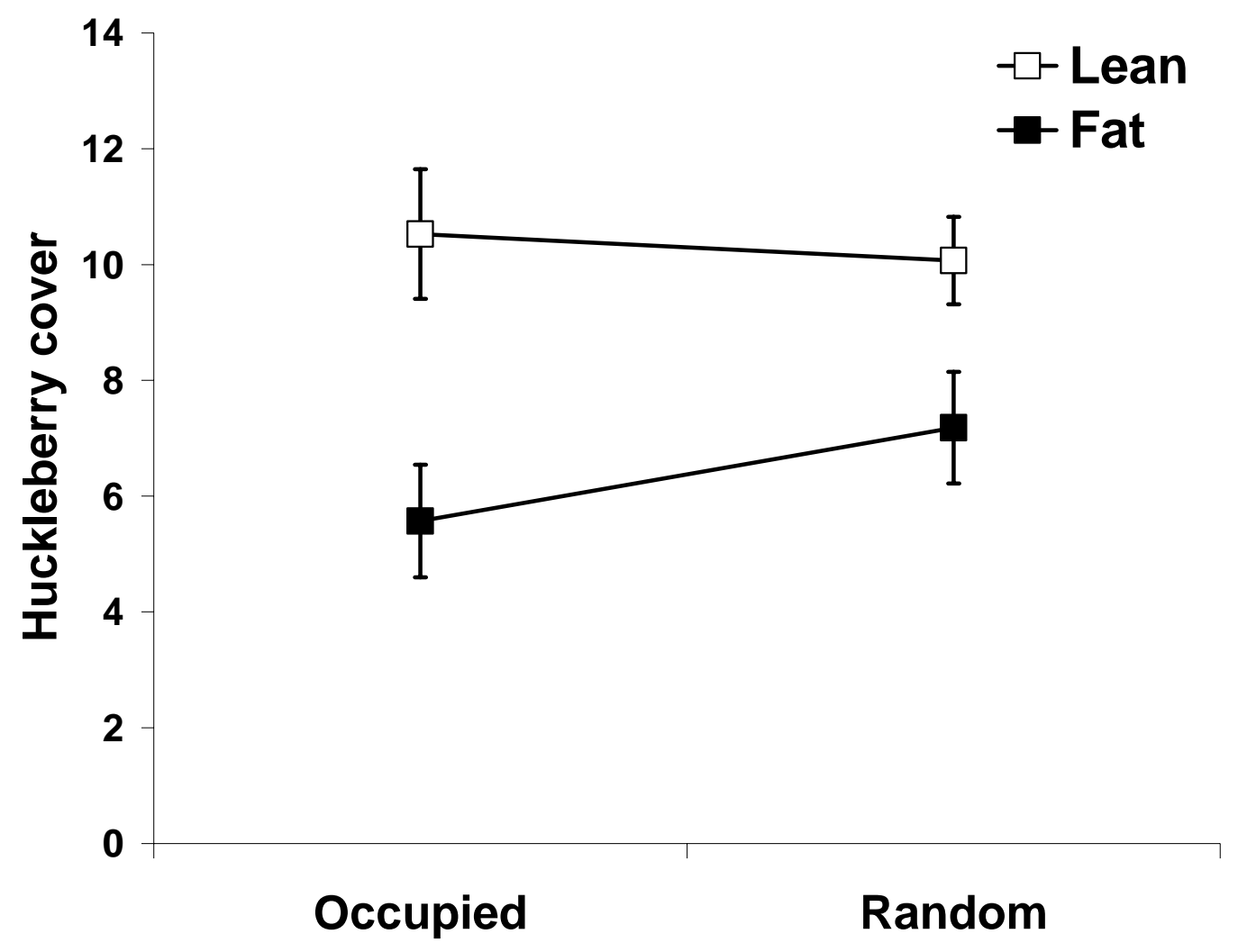

Figure 4. Mean huckleberry cover values ( $\pm 1 \mathrm{SE}$ ) of fat and lean Swainson's Thrushes from occupied and random points $(n=22)$. Huckleberry cover $(\mathrm{m})$ was measured along two $10 \mathrm{~m}$ line intercepts at five occupied and five random locations within each bird's home range. 


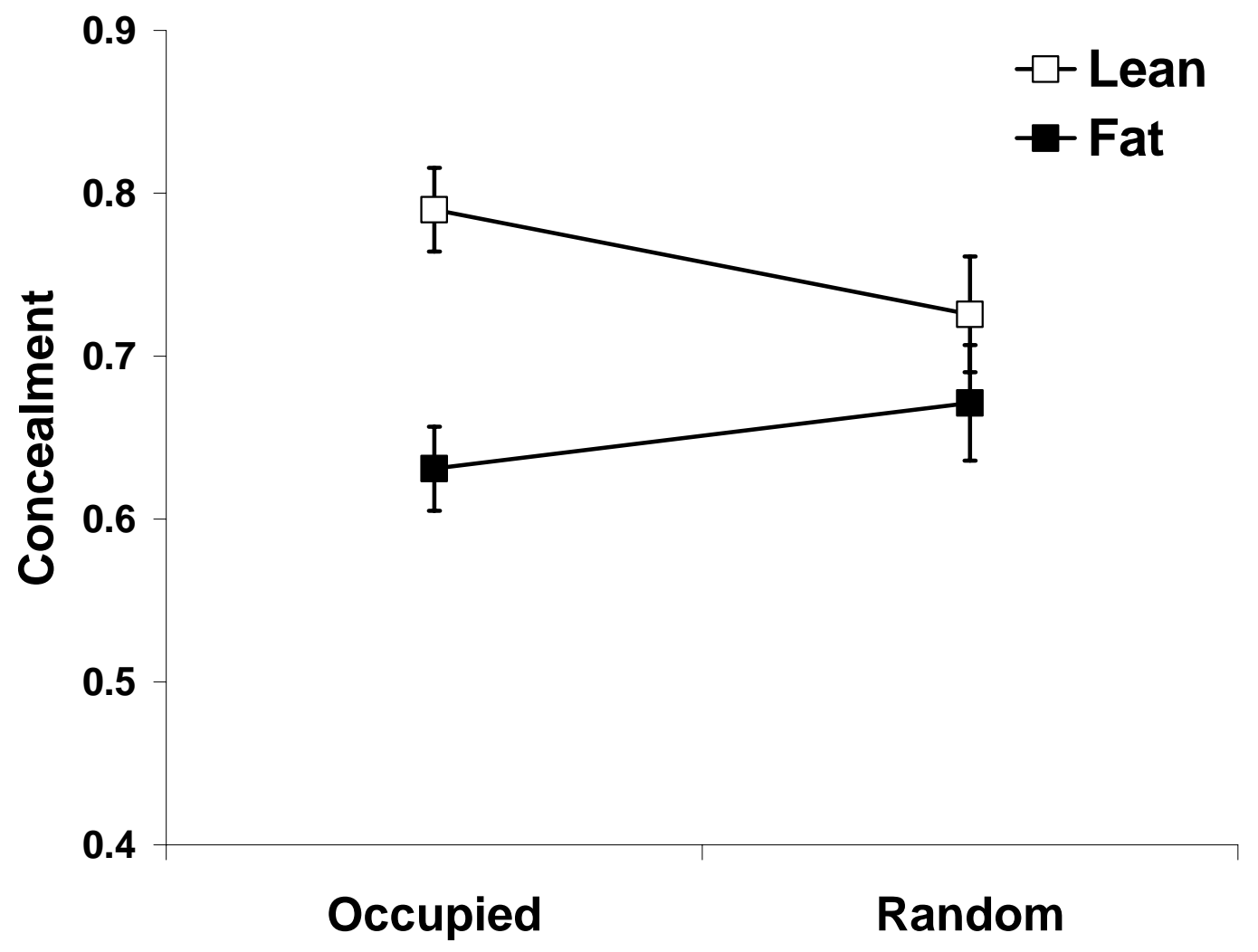

Figure 5. Mean concealment values ( $\pm 1 \mathrm{SE}$ ) for fat and lean Swainson's Thrushes at occupied and random points $(n=22)$. Concealment values are the proportion of 100 squares from a $1 \mathrm{~m}^{2}$ checkerboard greater than $50 \%$ obscured through $3 \mathrm{~m}$ of vegetation at five occupied and five random locations within each bird's home range. 


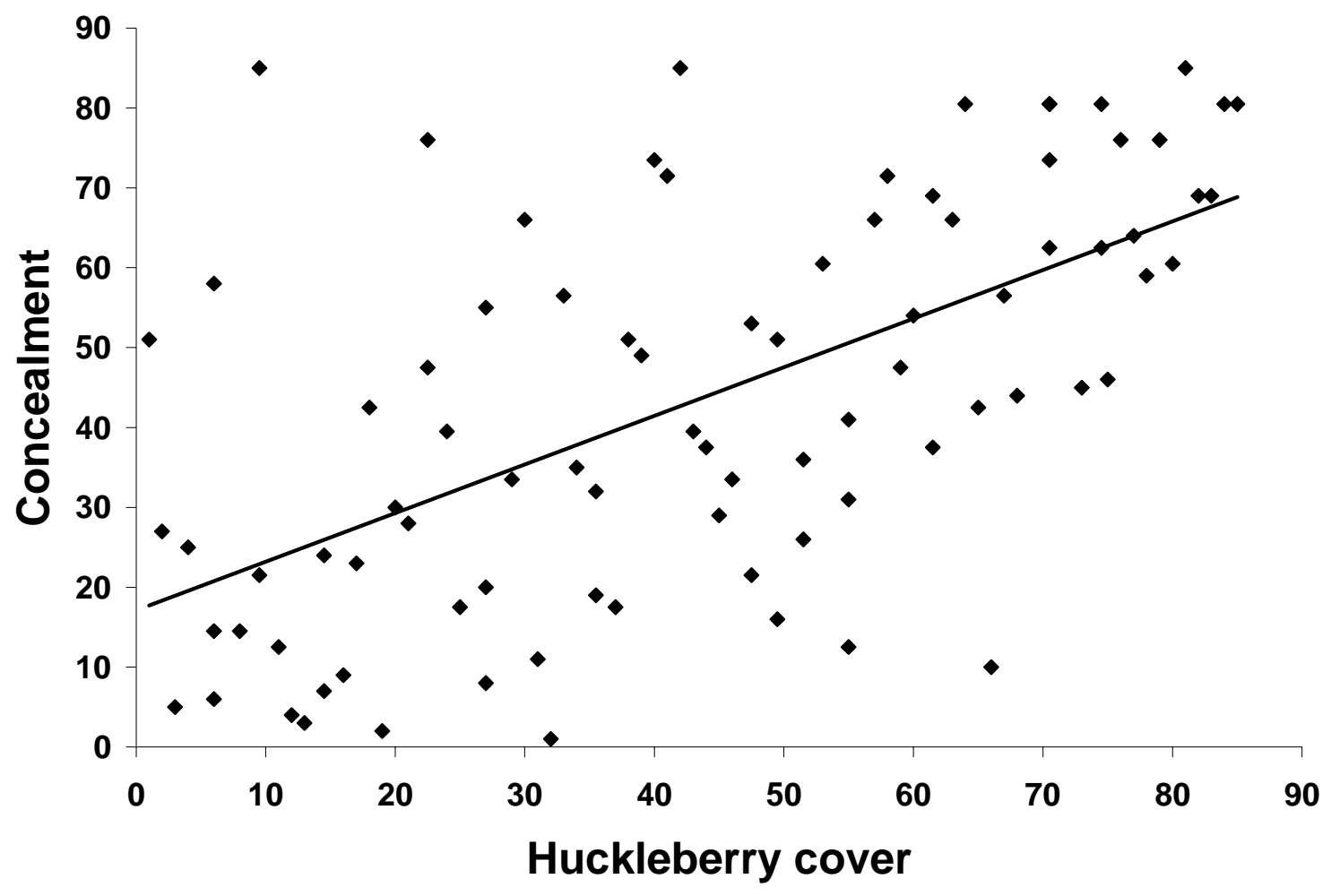

Figure 6. Spearman-rank correlation between concealment and huckleberry cover. Concealment and huckleberry cover values are ranks from five random locations within each bird's home range. 


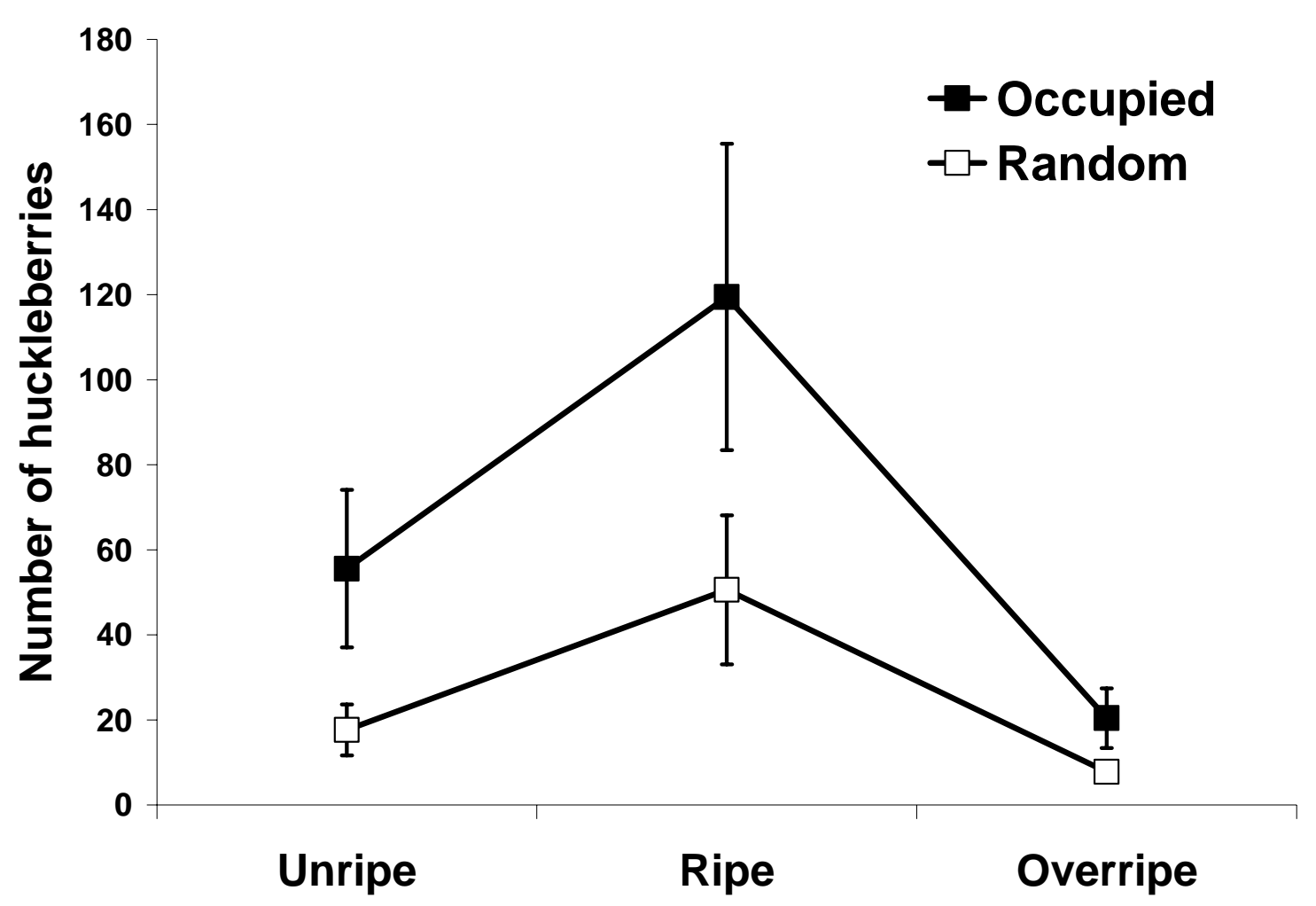

Figure 7. Mean numbers of unripe, ripe, and overripe huckleberries ( $\pm 1 \mathrm{SE})$ at occupied and random plots $\left(4 \mathrm{~m}^{2}\right)$ within Swainson's Thrush home ranges $(n=22)$. 
Occupied points contained twice as many ripe as unripe berries and six times as many ripe than overripe berries (Figure 7). However, these proportions were not significantly different between occupied and random points (Figure 7). Due to annual variation in the huckleberry crop, there was no significant difference in huckleberry abundance between conifer and broadleaf vegetation types at occupied and random points for both years combined $($ broadleaf $=154.2 \pm 105.5$, conifer $=132.1 \pm 19.0, P=0.74)$. In 2002 , there were 4 times as many huckleberries in broadleaf than in conifer (broadleaf $=423.7 \pm$ 283.1 , conifer $=108.7 \pm 18.5, P=0.03$, while in 2003 only six huckleberries were counted in broadleaf $($ broadleaf $=0.2 \pm 0.2$, conifer $=158.8 \pm 34.8, P=0.01)$. Although lean birds $(n=7)$ had 2.8 times as many huckleberries as fat birds $(n=15)$ at occupied points (Figure 8), this result was not statistically significant $(P=0.18)$ due to large variation and small sample size.

The most common types of foods in fecal samples from Swainson's Thrushes at Lanphere Dunes $(n=74)$ in descending order of frequency were arthropods $(87 \%)$, huckleberries (70\%), wax myrtle bracteoles (43\%), blackberry spp. (7\%), and salal (4\%). The mean number of huckleberry seeds per fecal sample was $8.1 \pm 1.3$ for all thrushes and $11.5 \pm 1.7$ for thrushes that had huckleberry seeds in their feces. The number of huckleberry seeds counted in fecal samples between birds captured in conifer and broadleaf did not differ significantly in 2002 (conifer $=6.8 \pm 2.6, n=16$, broadleaf $=4.1$ $\pm 2.1, n=7, P=0.55)$ or in $2003($ conifer $=9.5 \pm 2.2, n=28$, broadleaf $=8.5 \pm 2.8, n=$ $23, P=0.78)$. The presence of wax myrtle bracteoles in thrush feces was 1.6 times more likely in birds captured in broadleaf nets $(n=31)$ than in conifer $(n=43)$, but this was 


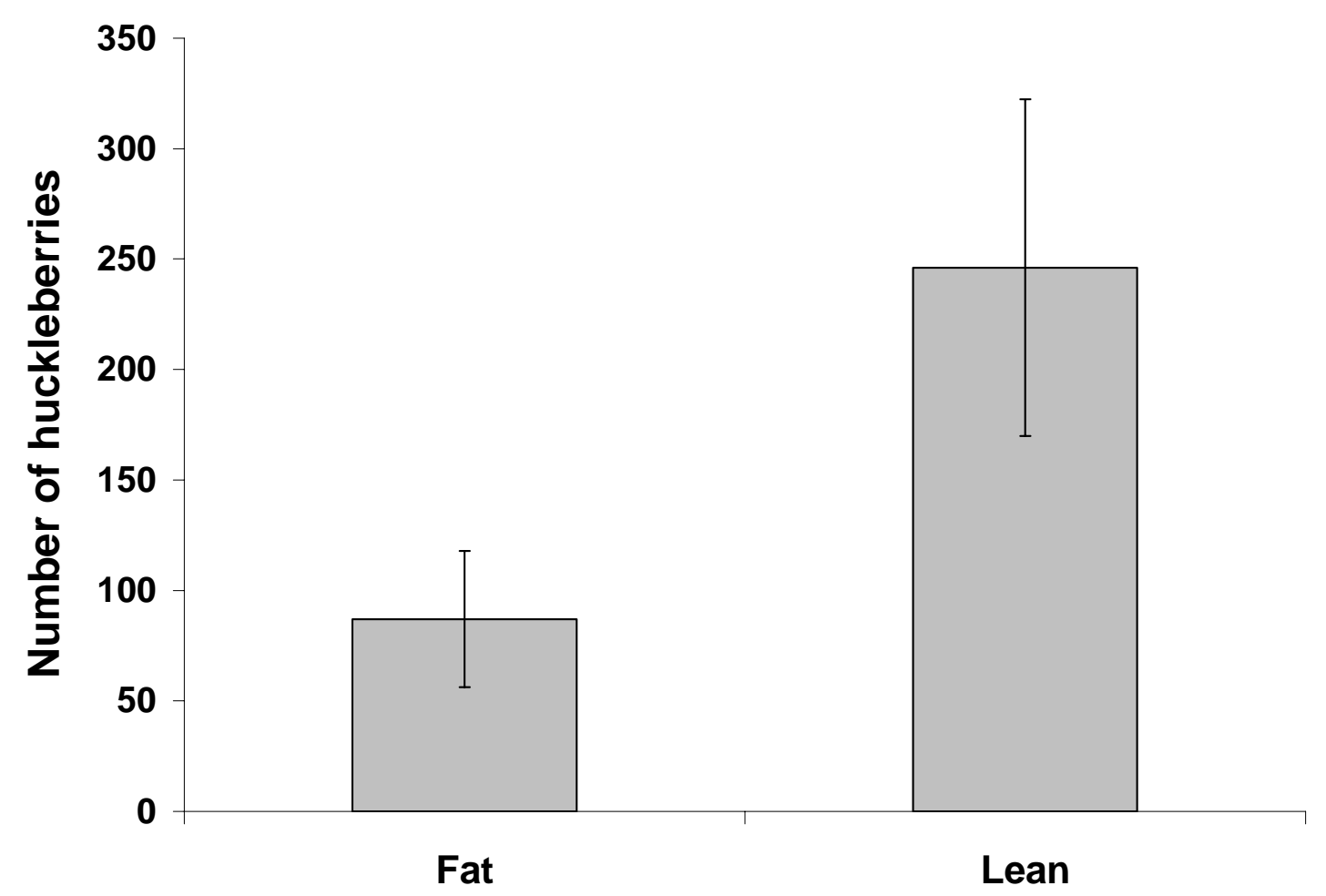

Figure 8. Mean values ( $\pm 1 \mathrm{SE}$ ) of huckleberries counted within $4 \mathrm{~m}^{2}$ occupied plots for fat $(n=7)$ and lean Swainson's Thrushes $(n=15)$. 
not statistically significant $\left(\right.$ broadleaf $=54.8 \%$, conifer $\left.=34.9 \%, \chi_{1}^{2}=3.72, P=0.05\right)$.

The number of huckleberry seeds (lean birds $=8.7 \pm 1.7$, fat birds $=4.4 \pm 1.9, P=0.20$ ) and the frequency of wax myrtle bracteoles (fat birds $=50.0 \%$, lean birds $=39.2 \%, \chi_{1}^{2}=$ $0.53, P=0.47)$ in the feces of fat $(n=14)$ and lean birds $(n=51)$ did not differ. 


\section{DISCUSSION}

My results suggest a complex stopover strategy for juvenile Swainson's Thrushes during fall migration. When all birds are pooled, it is difficult to discern much about their stopover ecology except that they appear to be associated with areas that have relatively high quantities of huckleberry. However, when birds are separated by energetic condition, it becomes apparent that lean and fat birds differ in their selection of microhabitats.

\section{Habitat Selection}

In contradiction to several previous studies on stopover ecology where habitats were used out of proportion to their availability (Hutto 1985, Martin and Karr 1986, Winker et al. 1992, Moore and Aborn 2000, Rodewald and Brittingham 2004, Sapir et al. 2004), juvenile Swainson's Thrushes in this study did not select among forest types at the scale of the study site $\left(2^{\text {nd }}\right.$ order $)$, or within their home ranges $\left(3^{\text {rd }}\right.$ order $)$. Since Swainson's Thrushes forage primarily in the understory (Mack and Yong 2000, personal observation), I expected that differences in the understory between forest types would have consequences on habitat selection. Considering the similarity in understory between the spruce and pine forest types, it was not surprising that birds did not noticeably select between these two. However, difference in shrub composition between the conifer and broadleaf forest types was marked (Table 1), and I expected to see the thrushes make a clear selection of one of these vegetation types. 
Several explanations may account for this apparent lack of habitat selection. During fall migration, Martin and Karr (1986) measured foliar cover of fruit bearing plants around mist nets at their study site and found that it correlated positively with net captures of frugivores like Swainson's Thrush. Although huckleberry, the most commonly ingested fruit determined by fecal samples, was seven times more common as a cover type in conifer than broadleaf forests (Table 1), the abundance of berries in the two forest types was not significantly different when the two years were combined. One confounding factor in this analysis is that the broadleaf forest points where huckleberries were abundant were actually small sun-exposed huckleberry fields at the border of conifer and broadleaf forest where conifer trees had blown down. This situation is probably similar to a tree-fall gap scenario where studies have found positive correlations between gaps and fruit, and gaps and frugivore abundance (Blake and Hoppes 1986, Martin and Karr 1986). The high density of huckleberries in these blow-down areas may partially explain why some birds were detected only in broadleaf in 2002. However, several birds also used broadleaf in 2003 when there were very few huckleberries counted in that forest type. Moreover, the blow-down locations were all close to conifer forest, so occupying these locations would not have appeared as avoidance of conifer in a Euclidean distance-based analysis.

Three major ecological features migrants may consider when selecting stopover habitat are food abundance, competition, and predation (Petit 2000). Depending on the energetic condition of an arriving migrant, different habitats may optimize a bird's abilities to meet those needs. For instance, Moore and Aborn (2000) found that spring 
migrant Summer Tanagers (Piranga rubra) differing in energetic needs used different stopover habitats. They found that fat birds rested in pine forests where concealment from raptors was greater, while lean birds chose to replenish their fuel reserves in the fruit-rich scrub/shrub habitat. Although I discovered differences in microhabitat selection between fat and lean birds for concealment and huckleberry cover, it was the lean birds that occupied more densely concealed microhabitats, and this did not result in selection of different forest types.

Habitat displacement of subordinates may occur when a limited food supply causes competition (Martin 1981, Moore and Yong 1991). Competition for preferred food-rich habitats erodes the ability to detect habitat selection when individuals are pooled because dominants occupy the preferred habitat and subordinates are forced into less preferred habitats. Although food did not appear to be limited since huckleberries and wax myrtle berries were still present and abundant in late October when the majority of the Swainson's Thrushes had already migrated south (personal observation), the remaining berries may have been in riskier areas where the reward was not sufficient to warrant their consumption by subordinates. This explanation could be investigated by testing the prediction that concealment values should be lower at locations where berries remain hanging in late October (after migrants have passed through the area) than at locations where berries have previously been removed.

A lack of habitat selection may also have occurred because birds had insufficient knowledge of the environment. Searching for the most appropriate habitat during stopover can be rewarding if that habitat is found, but it may also increase risk of 
predation and time spent searching instead of feeding (Alerstam and Lindström 1990). Shochat et al. (2002) found that sylviid warblers, during autumn migration in Israel, deviated from an ideal free distribution by over-exploiting a food-poor habitat compared to a nearby food-rich habitat, and they attributed this to a perceptual limitation of resource distribution and insufficient time for exploration. Since newly arriving juvenile Swainson's Thrushes would be naïve to the distribution of resources at Lanphere Dunes, it is possible that their lack of knowledge of the landscape caused them to distribute themselves amongst habitats haphazardly. On the other hand, most birds lingered for several days and the different habitats are adjoining. This should have allowed them to redistribute themselves after initial settling and subsequent exploration.

If migrants arrive with different nutritional needs, and different habitats contain different resources, then individual migrants might be expected to select habitats differently to replenish nutritional deficiencies, resulting in an overall appearance of no consistent habitat selection. Although huckleberry was the most frequent fruit found in fecal samples, and there were significantly more huckleberries at occupied sites than at random sites, huckleberries have low lipid and protein content (Norton et al. 1984) and thus may not contribute all of the nutrients necessary for efficient fat deposition (Bairlein 2002). Thus, some birds may have preferred lipid-rich fruits such as wax myrtle and spent more time in broadleaf forest where it was twice as common as in conifer. Lipidrich fruits such as wax myrtle may be preferred over sugar-rich fruits since lipids can be converted into fat more efficiently than can sugar (Bairlein 1998). Further research, such as volumetric analysis of fecal samples, nutrient content of fruits, and cage-controlled 
experiments, would be necessary to determine whether certain fruits at Lanphere Dunes are preferred over others, and whether energetic condition influences this preference.

Equally important and unmeasured in this study was the distributional abundance and composition of arthropods, which were found in $87 \%$ of all fecal samples. Fruit is generally low in protein and so thrushes could seek habitats where arthropods are more common in order to replenish protein stores and meet basal metabolic needs (Schwilch et al. 2002). Additionally, since Bairlein (2002) demonstrated that birds put on fat fastest when a fruit diet is mixed with insects, it would be particularly interesting to know if birds that include different habitats in their home range are benefiting from complementary food resources.

\section{Stopover Strategies: Fat vs. Lean}

Lean birds differed from fat birds by having significantly more huckleberry cover and more concealment at occupied points within their home ranges. Since lean birds need to put on more fat to migrate to the next stopover site, it was expected that lean birds would occupy locations where there was a greater food supply. Furthermore, since huckleberries were one of the most commonly eaten foods by Swainson's Thrushes, it was not surprising that lean birds would establish their home ranges in locations where huckleberry shrubs were abundant and occupy locations within their home ranges where huckleberries were plentiful. However, since huckleberry cover and concealment were positively correlated, it is not possible to say with certainty that lean birds were selecting locations based on food abundance or concealment from predators. Visually oriented 
predators are a significant hazard to stopover migrants at Lanphere Dunes. During my study, at least two birds with radio-transmitters (one during a preliminary season in 2001 and one in 2003) were captured and eaten by accipiters. If concealment is more of a priority than food at this study site, then huckleberries may just be the best food available within the dense huckleberry shrubs. In order to more fully understand the stopover strategy of lean birds, it will be necessary to determine the relative abundance of arthropod and wax myrtle (the two other primary food items found in fecal samples) within the study area, and how these food types rank in preference when predation hazard is controlled. Whether huckleberries or concealment were the priority for lean birds, these birds used a strategy at my study site that provided a reliable food source and dense cover.

Strategies for fat birds remain less clear. In contrast to lean birds, fat birds used more open microhabitats with fewer huckleberry shrubs and thus occupied seemingly more risk-prone locations than lean birds. There are two potential explanations for this. One possibility is that fat birds were subordinate to lean birds and were forced to occupy these locations due to conspecific interactions. If either huckleberries or concealment were a limited resource, then this may have been a possible scenario. However, huckleberries, although patchy in distribution, were still on the bushes months after the last of the Swainson's Thrushes had left. Moreover, the average concealment values for fat birds at occupied locations were actually lower, though not significantly so, than the average concealment values at random locations within their home ranges, within which they should be free to select. Additionally, the average home range size for fat birds was 
half that of lean birds suggesting that fat birds had sufficient resources in their smaller home ranges. This implies that fat birds were not forced to select the habitats they occupied.

Another possibility is that fat birds already had sufficient fuel stores to continue with migration and simply needed to avoid depredation. Although fat birds had significantly less concealment than lean birds, they had an average of $63 \% \pm 3 \%$ concealment at occupied locations, which may have been sufficient to avoid predators if they were not actively foraging. Additionally, the smaller home range size of fat birds might indicate that they did not need to search for food as much as lean birds. This scenario is somewhat different than that described by Moore and Aborn (2000) for spring migrant Summer Tanagers (Piranga rubra) on a barrier island off the coast of Mississippi where fat birds took shelter in pine forest and lean birds foraged in the more productive but more exposed scrub habitat. This difference is likely due to the fact that an important food source (i.e. huckleberry) at my study site was positively correlated with concealment.

\section{Conservation Implications}

During migration, birds arrive at stopover sites in various physiological states due to conditions experienced prior to leaving the previous stopover site or during flight. Once a migrant has landed at a stopover site, it must quickly assess its energetic condition and determine what habitat will best suit its particular requirements in order to proceed successfully with migration (Moore and Aborn 2000). In the western United States, 
coastal habitats are especially important for migratory songbirds where ecological barriers such as oceans tend to concentrate migrants into whatever forested habitats the birds first discover during landfall. However, migratory songbird stopover habitats have received little attention in the West, which has limited the ability of land managers to prioritize areas for songbird conservation.

This study documented that juvenile Swainson's Thrushes did not select for a particular forest type in this area during fall migration, which may indicate that a mixture of habitats is important to fulfill the stopover needs of different individuals. More importantly though, since not a single bird was seen or located in a non-forested environment, it can be inferred that Swainson's Thrushes avoided those habitats in favor of forest. Non-forested habitats would have been much riskier due to their lack of concealment and would have needed a considerable food reward to entice birds to use them. Furthermore, since this study documented high quantities of huckleberry in the forested habitats, the thrushes probably also avoided non-forested habitats because they did not contain the bird-disseminated fruits found in fecal samples of these birds. Thus, preserving forested habitats along the West Coast that contain bird-disseminated fruits and cover may in turn help protect the migrants that depend on them for refueling during their southbound migrations. 


\section{LITERATURE CITED}

Alerstam, T. and Å. Lindström. 1990. Optimal bird migration: the relative importance of time, energy, and safety. Pages 331-351 in E. Gwinner, editor. Bird migration: physiology and ecophysiology. Springer-Verlag, Berlin, Germany.

Bairlein, F. 1998. The effect of diet composition on migratory fuelling in Garden Warblers Sylvia borin. Journal of Avian Biology 29:546-551.

Bairlein, F. 2002. How to get fat: nutritional mechanisms of seasonal fat accumulation in migratory songbirds. Naturwissenschaften 89:1-10.

Blake, J. G. and W. G. Hoppes. 1986. Influence of resource abundance on use of treefall gaps by birds in an isolated woodlot. Auk 103:328-340.

Burns, K. C. 2002. Seed dispersal facilitation and geographic consistency in bird-fruit abundance patterns. Global Ecology and Biogeography 11:253-259.

Conner, L. M. and B. W. Plowman. 2001. Using Euclidean distances to assess nonrandom habitat use. Pages 275-290 in J. J. Millspaugh and J. M. Marzluff, editors. Radio tracking and animal populations. Academic Press, San Diego, California.

Conner, L. M., M. D. Smith, and L. W. Burger. 2003. A comparison of distance-based and classification-based analyses of habitat use. Ecology 84:526-531.

ESRI. 2002a. ArcInfo. Version 8.2. Environmental Science Research Institute, Inc. Redlands, California.

ESRI. 2002b. ArcView. Version 3.3. Environmental Science Research Institute, Inc. Redlands, California.

Hedenström, A. and T. Alerstam. 1997. Optimal fuel loads in migratory birds: distinguishing between time and energy minimization. Journal of Theoretical Biology 158:227-234.

Hintze, J. 2001. NCSS and PASS. Number Cruncher Statistical Systems. Kaysville, Utah. Available at www.ncss.com. 
Hooge, P. N. and B. Eichenlaub. 2000. Animal movement extension to ArcView. Version 2.0. Alaska Science Center - Biological Science Office, United States Geological Survey, Anchorage, Alaska.

Hutto, R. L. 1985. Seasonal changes in the habitat distribution of transient insectivorous birds in Southeastern Arizona: competition mediated? Auk 102:120-132.

Johnson, D. H. 1980. The comparison of usage and availability measurements for evaluating resource preference. Ecology 61:65-71.

Lindström, Å. 1990. The role of predation risk in stopover habitat selection in migrating Bramblings Fringilla montifringilla. Behavioral Ecology 1:102-106.

LOAS. 2004. Location of a Signal. Version 3.0.2. Ecological Software Solutions. Urnäsch, Switzerland.

Loria, D. E., and F. R. Moore. 1990. Energy demands of migration on Red-eyed Vireos (Vireo olivaceous). Behavioral Ecology 1:24-35.

Mack, D. E., and W. Yong. 2000. The Swainson's Thrush (Catharus ustulatus). In A. Poole and F. Gill, editors. The birds of North America, No. 540. The Academy of Natural Sciences, Philadelphia, PA, and the American Ornithologists' Union, Washington, DC.

Marra, P. P. 2000. The role of behavioral dominance in structuring patterns of habitat occupancy in a migrant bird during the nonbreeding season. Behavioral Ecology 11:299-308.

Martin, T. E. 1981. Limitation in small habitat islands: chance or competition? Auk 98:715-734.

Martin, T. E. and J. R. Karr. 1986. Patch utilization by migrating birds: resource oriented? Ornis Scandinavica 17:165-174.

Moore, F. R. 2000. Stopover ecology of Nearctic-Neotropical landbird migrants: habitat relations and conservation implications (preface). Studies in Avian Biology 20:1-3.

Moore, F. R., and D. A. Aborn. 2000. Mechanisms of en route habitat selection: how do migrants make habitat decisions during stopover? Studies in Avian Biology 20:3442.

Moore, F. R. and W. Yong. 1991. Evidence of food-based competition among passerine migrants during stopover. Behavioral Ecology and Sociobiology 28:85-90. 
Norris, R. N., P. P. Marra, T. K. Kyser, T. W. Sherry, and L. M. Ratcliffe. 2004. Tropical winter habitat limits reproductive success on the temperate breeding grounds in a migratory bird. Proceedings of the Royal Society of London Series B 271:59-64.

Norton, H. H., E. S. Hunn, C. S. Martinsen, and P. B. Keely. 1984. Vegetable food products of the economies of the Pacific Northwest. Ecology of Food and Nutrition 14:219-228.

Perkins, M. W., and L. M. Conner. 2004. Habitat use of fox squirrels in southwestern Georgia. Journal of Wildlife Management 68:509-513.

Petit, D. R. 2000. Habitat use by landbirds along Nearctic-Neotropical migration routes: implication for conservation of stopover habitats. Studies in Avian Biology 20:1533.

Ralph, C. J. 1971. An age differential of migrants in coastal California. Condor 73:243246.

Ralph, C. J., G. R. Geupel, P. Pyle, T. E. Martin, and D. F. DeSante. 1993. Handbook of field methods for monitoring landbirds. USDA Forest Service General Technical Report PSW-GTR-144, Albany, California.

Rappole, J. H. and A. R. Tipton. 1991. New harness design for attachment of radio transmitters to small passerines. Journal of Field Ornithology 62:335-337.

Rodewald, P. G. and M. C. Brittingham. 2004. Stopover habitats of landbirds during fall: use of edge-dominated and early-successional forests. Auk 121:1040-1055.

Sapir, N., Z. Abramsky, E. Shochat, and I. Izhaki. 2004. Scale-dependent habitat selection in migratory frugivorous passerines. Naturwissenschaften 91:544-547.

SAS Institute. 2001. SAS/STAT Software. Version 8.2. SAS Institute Inc. Cary, North Carolina.

Schaub, M. and L. Jenni. 2001. Variation of fuelling rates among sites, days and individuals in migrating passerine birds. Functional Ecology 15:584-594.

Schmaljohann, H. and V. Dierschke. 2005. Optimal bird migration and predation risk: a field experiment with northern wheatears Oenanthe oenanthe. Journal of Animal Ecology 74:131-138. 
Schwilch, R., A. Grattarola, F. Spina, and L. Jenni. 2002. Protein loss during longdistance migratory flight in passerine birds: adaptation and constraint. The Journal of Experimental Biology 205:687-695.

Shochat, E., Z. Abramsky, B. Pinshow, and M. E. A. Whitehouse. 2002. Densitydependent habitat selection in migratory passerines during stopover: what causes the deviation from IFD? Evolutionary Ecology 16:469-488.

Sillet, T. S. and R. T. Holmes. 2002. Variation in survivorship of a migratory songbird throughout its annual cycle. Journal of Animal Ecology 71:296-308.

Smith, R. J. and F. R. Moore. 2005. Arrival timing and seasonal reproductive performance in a long-distance migratory landbird. Behavioral Ecology and Sociobiology 57:231-239.

Stransky, J. J. and L. K. Halls. 1980. Fruiting of woody plants affected by site preparation and prior land use. Journal of Wildlife Management 44:258-263.

Stutchbury, B. J. 1994. Competition for winter territories in a neotropical migrant: the role of age, sex and color. Auk 111:63-69.

Thomas, D. L. and E. J. Taylor. 1990. Study designs and tests for comparing resource use and availability. Journal of Wildlife Management 54:322-330.

Thompson, J. N., and M. F. Willson. 1979. Evolution of temperate fruit/bird interactions: phonological strategies. Evolution 33:973-982.

Winker, K., D. W. Warner, and A. R. Weisbrod. 1992. The Northern Waterthrush and Swainson's Thrush as transients at a temperate inland stopover site. Pages 384-402 in J. M. Hagan and D. W. Johnston, editors. Ecology and conservation of neotropical migrant landbirds. Smithsonian Institution Press, Washington, DC.

Yong, W., and F. R. Moore. 1997. Spring stopover of intercontinental migratory thrushes along the northern coast of the Gulf of Mexico. Auk 114:263-278. 